\section{Cureus}

Received 08/07/2016

Review began 08/11/2016

Review ended 11/07/2016

Published 11/09/2016

\section{(c) Copyright 2016}

Spector et al. This is an open access article distributed under the terms of the Creative Commons Attribution License CC-BY 3.0., which permits unrestricted use, distribution, and reproduction in any medium, provided the original author and source are credited.

\title{
The Influence of the Menstrual Phases on Polysomnography
}

\author{
Andrew R. Spector ${ }^{1}$, Daniel Loriaux ${ }^{2}$, Diana Alexandru ${ }^{3}$, Sanford H. Auerbach ${ }^{4}$ \\ 1. Department of Neurology, Duke University Medical Center, Durham, NC 2. Internal Medicine, Brigham \\ \& Women's Hospital, Harvard Medical School, Boston, USA 3. Pulmonary Disease, Critical Care \\ Medicine, Elliot Health System 4. Neurology, Boston University School of Medicine
}

$\square$ Corresponding author: Daniel Loriaux, dloriaux@bwh.harvard.edu

Disclosures can be found in Additional Information at the end of the article

\section{Abstract}

Purpose: The primary objective of this study is to determine how the phases of the menstrual cycle influence the results of polysomnography (PSG).

Methods: Twenty-eight adult subjects who reported regular menstrual periods, last menstrual period (LMP) within 26 days of their PSG, no exogenous hormone use, no history of polycystic ovarian syndrome, and who were scheduled for diagnostic PSG at Boston Medical satisfied inclusion criteria for the study. These subjects were divided into a Follicular Cohort (days 0-13 of the cycle) or Luteal Cohort (days 14-26 of the cycle), and a one-way analysis using a t-test was performed to test the hypothesis that the follicular phase confers protection against obstructive sleep apnea (OSA). A likelihood-ratio chi-square test was also applied to assess for a statistically significant association between menstrual stage and the presence of moderate-tosevere sleep apnea (apnea-hypopnea index (AHI) > 15/h). Thus, the statistical analysis was performed using AHI as both a continuous and a categorical outcome.

Results: The mean AHI for patients in the Follicular Cohort $(6.1 / \mathrm{h})$ was significantly lower than the Luteal Cohort (14.3/h, p = 0.033). In the Follicular Cohort, 12\% of patients had moderate to severe OSA. In the Luteal Cohort, $46 \%$ of patients had moderate to severe OSA ( $p=0.045)$.

Conclusions: Subjects undergoing PSG during the follicular phase have significantly lower AHIs than those in the luteal phase. Thus, the timing of PSG acquisition for regularly menstruating women should be considered when interpreting results.

Categories: Neurology, Pulmonology

Keywords: menstrual cycle, obstructive sleep apnea, polysomnography

\section{Introduction}

Female sex hormones, including estrogen and progesterone, are thought to have a protective effect against obstructive sleep apnea (OSA), which manifests as decreased rates of OSA in regularly menstruating ("premenopausal”) women compared to postmenopausal women or men [1].

The physiologic rationale for the pro-respiratory function of estrogen and progesterone in OSA is multifactorial: (1) both hormones increase pharyngeal dilator muscle activity, thereby resisting a collapse of the upper airway during sleep, (2) both hormones promote hypoxic and hypercapnic ventilatory responses, (3) estrogen inhibits overexpression of hypoxia-inducible 


\section{Cureus}

factor-1 (HIF-1), a transcription factor that is responsible for decreasing resistance to fatigability in the genioglossus muscle, and (4) progesterone acts on the nuclear progesterone receptor (nPR) transcription factor to augment the ventilatory response to hypoxia [2-5].

Although estrogen and progesterone share redundancy of function as activators of the pharyngeal dilator muscles and stimulators of the respiratory centers, prior clinical research on estrogen and progesterone therapy suggests that there are distinct differences in the therapeutic efficacy for each hormone [6-10]. No study of progesterone monotherapy has demonstrated a therapeutic benefit for obstructive sleep apnea (Table 1). Furthermore, there is evidence that progesterone supplementation in combination with estrogen therapy may attenuate the respiratory benefits of estrogen alone [6].

\begin{tabular}{|c|c|c|c|c|c|}
\hline Study & Cohort & Supplement & Study Design & PSG Findings & Conclusions \\
\hline $\begin{array}{l}\text { Keefe, et } \\
\text { al., } \\
1999 \text { [11] }\end{array}$ & $\begin{array}{l}5 \\
\text { postmenopausal } \\
\text { women }\end{array}$ & $\begin{array}{l}\text { Estrogen \& } \\
\text { Combination }\end{array}$ & $\begin{array}{l}\text { 17-beta-estradiol (E2) for } \\
\text { 3-4 weeks followed by E2 } \\
+ \text { medroxyprogesterone } \\
\text { acetate (MPA) for } 10-12 \\
\text { days. }\end{array}$ & $\begin{array}{l}\mathrm{E} 2 \text { or } \mathrm{E} 2+\mathrm{P} \text { both had } \\
\text { therapeutic benefit in all } \\
\text { patients. }\end{array}$ & $\begin{array}{l}\text { Estrogen } \\
\text { supplementation or } \\
\text { combined therapy } \\
\text { has therapeutic } \\
\text { benefit in the } \\
\text { treatment of OSA. } \\
\text { Progesterone } \\
\text { monotherapy, } \\
\text { however, does not } \\
\text { alleviate sleep apnea } \\
\text { severity in } \\
\text { menopausal women. }\end{array}$ \\
\hline $\begin{array}{l}\text { Block, et } \\
\text { al., } \\
1981[12]\end{array}$ & $\begin{array}{l}21 \\
\text { postmenopausal } \\
\text { women }\end{array}$ & Progesterone & $\begin{array}{l}11 \text { women received } 30 \text { mg } \\
\text { medroxyprogesterone } \\
\text { (MPG) daily. } 10 \text { women } \\
\text { received placebo control } \\
\text { in a randomized, double- } \\
\text { blind control study. }\end{array}$ & $\begin{array}{l}\text { Total AHI prior to MPG } \\
\text { therapy was } 7.6(+/-12.7) \\
\text { and } 5.7(+/-15) \text { post-MPG } \\
\text { therapy. The number of } \\
\text { recorded apneas increased } \\
\text { from } 4.4(+/-9) \text { pre-MPG to } 5 \\
(+/-14) \text { post-MPG. }\end{array}$ & $\begin{array}{l}\text { There is no } \\
\text { therapeutic benefit of } \\
\text { medroxyprogesterone } \\
\text { monotherapy for } \\
\text { OSA. }\end{array}$ \\
\hline $\begin{array}{l}\text { Pickett, et } \\
\text { al., } \\
1989 \text { [13] }\end{array}$ & $\begin{array}{l}9 \\
\text { postmenopausal } \\
\text { women }\end{array}$ & Combination & $\begin{array}{l}\text { Nine healthy, non-obese } \\
\text { postmenopausal women } \\
\text { received placebo or } \\
\text { combined MPA ( } 20 \text { mg } \\
\text { TID) and estrogen } \\
\text { (conjugated equine } \\
\text { estrogens, Premarin, } 1.25 \\
\text { mg BID) therapy for } 1 \text { - } \\
\text { week duration. }\end{array}$ & $\begin{array}{l}\text { Combined therapy decreased } \\
\text { the total number of sleep- } \\
\text { disordered breathing } \\
\text { episodes from } 137 / \text { night to } \\
28 / \text { night. }\end{array}$ & $\begin{array}{l}\text { Combined exogenous } \\
\text { estrogen and } \\
\text { progestin therapy } \\
\text { reduced the number } \\
\text { of sleep-disordered } \\
\text { breathing episodes in } \\
\text { healthy, non-obese, } \\
\text { postmenopausal } \\
\text { women. }\end{array}$ \\
\hline $\begin{array}{l}\text { Manber, et } \\
\text { al., }\end{array}$ & postmenopausal & $\begin{array}{l}\text { Estrogen \& } \\
\text { Combination }\end{array}$ & $\begin{array}{l}\text { All subjects underwent } 4 \\
\text { sequential PSG analyses: } \\
\text { (1) after no HRT, (2) after } \\
\text { two nights on HRT, (3) } \\
\text { after 7-12 days on }\end{array}$ & $\begin{array}{l}\text { Estrogen monotherapy was } \\
\text { associated with significant } \\
\text { reduction in Total } \mathrm{AHI} \\
\text { ( } 22.7 / \text { hour to } 12.2 / \text { hour). In } \\
\text { contrast, there was no }\end{array}$ & $\begin{array}{l}\text { Estrogen has a } \\
\text { substantial benefit on } \\
\text { OSA in } \\
\text { postmenopausal } \\
\text { women, but these } \\
\text { beneficial effects of }\end{array}$ \\
\hline
\end{tabular}




\section{Cureus}

2003 [6] women

Cistulli, et 10

al., postmenopausal

1994 [14] women

Polo-

Kantola, et

al.,

2003 [15]

Strohl, et

al.,

1981 [10]

\section{Cook, et}

al.,

10 Men

1989 [8]

Rajagopal,

et al.,

62 women

9 adult patients:

8 Men 1 Woman postmenopausal Estrogen

Progesterone all patients in the study, both at baseline and 1-6 weeks following MPA monotherapy (60-120 mg daily).

The therapeutic efficacy of short-term hormone replacement therapy was studied with either estrogen alone or in combination with progesterone supplementation for 50 days.

Prospective randomized placebo-controlled doubleblind crossover study.$$
\text { daily). }
$$

.

All ten patients underwent initial PSG before entering a double-blind crossover study using MPA 150 mg daily or placebo.

Treatment was continued for 1-week and then followed by a second polysomnogram. A 3-week washout period separated MPA therapy and placebo trial.

PSG was performed before and after a 4-week treatment period with MPA

Progesterone
(60 mg daily) and once
Neither estrogen nor combined therapy with estrogen and progesterone achieved a significant reduction in $\mathrm{AHI}$. Although no change in hypercapnic ventilatory responsiveness was observed, there was an increase in hypoxic ventilatory responsiveness.

\section{Estrogen replacement}

therapy decreased the

occurrence $(p=0.047)$ and

frequency $(p=0.049)$ of sleep apnea.

MPA therapy was associated with significant reduction in

$\mathrm{PaCO} 2$ and increase in

$\mathrm{PaO} 2$. Four of the 9 patients reported resolution of daytime somnolence and disappearance of pedal edema with significant weight reduction in 3 of those 4 . For these four patients, a significant reduction in the frequency of obstructive apneas was achieved.

estrogen HRT are attenuated when progesterone is included.

Short-term HRT is ineffective in the clinical management of postmenopausal women with OSA.

Unopposed estrogen replacement therapy has a minor therapeutic effect on OSA.

Although MPA monotherapy can have a beneficial therapeutic effect in patients with OSA, this is a heterogeneous patient population and this effect is not achieved in all subjects.

No changes in the frequency of respiratory events, the mean duration of respiratory events, or mean fall in $\mathrm{O} 2$ saturation was achieved for patients treated with MPA.

No significant differences in MPA monotherapy does not improve disordered breathing during sleep in the 


\section{Cureus}

1986 [7]

$\begin{array}{ll}\text { Franklin, } & 1 \\ \text { et al., } & \text { premenopausal } \\ 1991 \text { [9] } & \text { woman }\end{array}$

4

Wesstrom, postmenopausal

et al., women, 1

2005 [16] perimenopausal woman.

Bixler, et 1,741 Subjects:

al., 1,000 Women

2001 [1] $741 \mathrm{Men}$

Shahar, et

al.,

2,852 Women

2003 [17]

(Age $>50$ ) again one week following

cessation of treatment.

Patient refused CPAP

therapy and was

prescribed combination

estradiol $(2 \mathrm{mg}$ ) daily with

MPG (5 mg) daily for the

first 10 days of every other

month. When medication

therapy was discontinued, symptoms returned. Re-

initiation of combination

therapy once again

achieved symptom

resolution.

Patients received baseline

PSG followed by

combination HRT (2 mg

estradiol, $0.5 \mathrm{mg}$

Combination

trimegestone) orally for 5-

6 weeks. Repeat PSG was

performed to assess

therapeutic effect of

combination HRT.

Cross-sectional,

observation study in which

1,741 subjects underwent

Combination

PSG and sleep apnea

severity in HRT patients

was contrasted against

nonusers.

This was an observational

study in which $\mathrm{AHI}$ was

measured for all patients

via a single-night, home

sleep study. OSA was

defined in the study as

Combination achieved.

non-hypercapnic

patient with OSA

Repeat PSG following 1-year of therapy (during estrogen monotherapy) confirmed improvement in OSA.

Mean Total AHI was used as the outcome measure for the study. The mean Total AHI prior to 5-6 week treatment phase with combination HRT was 14.9. Following

treatment, the mean Total $\mathrm{AHI}$ across all subjects had been reduced to 3.9 . This represents a $75 \%$ reduction.

OSA prevalence in premenopausal women: $0.6 \%$. OSA prevalence in postmenopausal women on HRT: $0.5 \%$. OSA prevalence in postmenopausal women without HRT: $2.7 \%$. OSA prevalence in men: $3.9 \%$

OSA prevalence in HRT users: $6.72 \%$. OSA having an $\mathrm{AHI}$ greater than prevalence in non-users: or equal to 15 . The $14.70 \%$.

prevalence of OSA in women receiving HRT was contrasted against non-users. complete OSA

\section{Estrogen}

monotherapy (daily)

alternating with combined therapy (first 10 days, every other month) led to resolution in a $45 \mathrm{y} / \mathrm{o}$ female patient.

\section{Combination HRT} offers an effective alternative therapy for patients affected by OSA.

Combination HRT reduces the risk of sleep apnea that is associated with menopause.

Combination HRT could have a therapeutic role in the alleviation of sleep apnea.

\section{TABLE 1: Prior Investigations of the Therapeutic Benefit for HRT in OSA}




\section{Cureus}

AHI: apnea-hypopnea index; HRT: hormone replacement therapy; MPA: medroxyprogesterone acetate; MPG:

medroxyprogesterone; OSA: obstructive sleep apnea; PSG: polysomnography

Only one study, a 62-patient prospective randomized crossover study conducted by PoloKantola, et al., investigated short-term unopposed estrogen replacement monotherapy for menopausal OSA patients [15]. Notably, the Polo-Kantola study demonstrated a detectable therapeutic benefit of estrogen monotherapy with decreased occurrence and frequency of sleep apnea [15]. The analogous natural state of elevated estrogen in premenopausal women occurs during the follicular phase of the menstrual cycle. Therefore, rising follicular estrogen as patients approach mid-cycle ovulation could similarly translate into reduced frequency and severity of sleep-disordered breathing on PSG. We hypothesized that premenopausal women would demonstrate lower sleep apnea severity during the follicular phase of the menstrual cycle, the time of highest unopposed estrogen.

\section{Materials And Methods}

\section{Procedure}

Permission for this study was obtained from the Boston University Institutional Review Board. Informed consent was obtained from all individual participants included in the study. This study consisted of a chart review of all female patients who underwent polysomnography at the Boston Medical Center Sleep Disorders Center between September 15, 2012 and March 15, 2013 who could recall the first day of their last menstrual period (LMP) and were not using exogenous sex hormones. In order to be included, subjects had to report an LMP of no more than 26 days prior to the study to avoid the potential confounder of early pregnancy. Subjects were excluded if they reported "irregular" menstrual periods or a history of polycystic ovarian syndrome (PCOS). All women included in the study were referred for PSG to evaluate for obstructive sleep apnea. Women referred for PSG with a multiple sleep latency test (MSLT) were excluded.

As eligible subjects were identified, their polysomnogram reports were reviewed to determine the overall apnea-hypopnea index (AHI), rapid eye movement (REM) AHI, and non-rapid eye movement (NREM) AHI. The subjects' pre-study questionnaires were reviewed to obtain additional baseline characteristics, such as body mass index, race, and recent alcohol use. Subjects were then grouped by LMP. Subjects who reported their LMP within 0-13 days from the date of their PSG were placed in the "Follicular Cohort" while subjects with an LMP 14-26 days prior to their PSG were placed in the "Luteal Cohort".

\section{Polysomnography}

The digital PSG consisted of the simultaneous recording of electroencephalogram, electrooculogram, electromyogram, electrocardiogram, respiratory effort, thermistor respiratory flow, nasal pressure, pulse oximetry, leg movement, body position, sound, video, and positive airway pressure device. The Viasys Somnostar version 9-1b recording equipment (SensorMedics, Yorba Linda, CA) was used.

The AHI was calculated as the total number of apneas, plus hypopneas, per hour with hypopneas defined as a flow reduction with a 3\% oxygen desaturation or an arousal.

\section{Questionnaires}

Prior to undergoing PSG, all patients completed a medical history questionnaire. Questions 


\section{Cureus}

include assessments of daytime sleepiness, medical history (including menstrual history), prescription and illicit drug use, alcohol use on the day of the test, caffeine use, and typical sleep habits. Additional screening questions consisted of last reported menstrual period as well as any past medical history of irregular menses or PCOS.

\section{Statistical analysis}

AHI was evaluated both as a continuous dependent variable and as a categorical dependent variable with a moderate-to-severe OSA cutoff (AHI > 15/h). A one-way analysis was performed using a t-test to compare the mean overall AHI in the Follicular Cohort with the Luteal Cohort. This analysis was repeated for REM AHI and NREM AHI. A likelihood-ratio chi-square test was applied to assess for a statistically significant association between the stage of the menstrual cycle and $\mathrm{AHI}>15 / \mathrm{h}$.

\section{Results}

Twenty-eight subjects satisfied inclusion criteria for the study. The Follicular Cohort was comprised of 17 women and the Luteal Cohort consisted of 11 women. In the Follicular Cohort, there was one woman who self-identified as White, eight as Hispanic, six as Black, and two who did not report a race. The Luteal Cohort was comprised of two Whites, five Hispanics, one Black, one Indian, and two who did not report a race. None of the women reported drinking any alcohol on the day of the study.

The mean age for all women was 39.3 years (range: 28 - 51). The mean age in the Follicular Cohort was 37.9 years (range: 28 - 50) compared to 42.3 years (range: 29 - 51) in the Luteal Cohort ( $\mathrm{p}=0.115$ ) (Table 2). Age was assessed as a potential confounding variable within the dataset and confirmed to have no statistically significant influence on the reported results $(\mathrm{p}=$ 0.388).

\begin{tabular}{|c|c|c|c|c|c|}
\hline Cohort & Total Subjects & BMI $\left(\mathrm{kg} / \mathrm{m}^{2}\right)$ & Age (Years) & Age Range (Years) & Epworth \\
\hline Follicular & 17 & 33.9 & 37.9 & $28-51$ & 9.7 \\
\hline Luteal & 11 & 31.8 & 42.3 & $29-51$ & 8.1 \\
\hline
\end{tabular}

\section{TABLE 2: Summary of Cohort Demographics}

BMI: body mass index

The mean Epworth Sleepiness Scale score for all women was 9.5. In the Follicular Cohort, the mean was 9.7 (range: 0 - 17). In the Luteal Cohort, the mean was 8.1 (range: 0 - 22, p = 0.08 ) (Table 2).

The mean body mass index (BMI) for all women was $33.7 \mathrm{~kg} / \mathrm{m} 2$. In the Follicular Cohort, the mean was $33.9 \mathrm{~kg} / \mathrm{m} 2$ (range: 21.7 - 50.7). In the Luteal Cohort, the mean was $31.8 \mathrm{~kg} / \mathrm{m} 2$ (range: $23-41.8, \mathrm{p}=0.40$ ) (Table 2$)$.

The mean overall AHI in the Follicular Cohort (6.1/h) was significantly lower than in the Luteal Cohort $(14.3 / \mathrm{h})(\mathrm{p}=0.033$, Figure 1). The mean REM AHI in the Follicular Cohort was $15.1 / \mathrm{h}$ versus $30.9 / \mathrm{h}$ in the Luteal group ( $\mathrm{p}=0.099$ ). The mean NREM AHI was $3.6 / \mathrm{h}$ in the Follicular 


\section{Cureus}

Cohort versus $7.8 / \mathrm{h}$ in the Luteal Cohort $(\mathrm{p}=0.108)$. The mean supine AHI in the Follicular Cohort was $10.2 / \mathrm{h}$ versus $20.6 / \mathrm{h}$ in the Luteal Cohort $(\mathrm{p}=0.09)$. The mean non-supine AHI in the Follicular Cohort was $3.1 / \mathrm{h}$ versus $10.0 / \mathrm{h}$ in the Luteal Cohort $(\mathrm{p}=0.09)$. Of the women who underwent PSG during the follicular phase, $12 \%$ had an overall AHI greater than $15 / \mathrm{h}$. In the Luteal Cohort, $46 \%$ of patients had an overall AHI greater than $15 / \mathrm{h}(\mathrm{p}=0.045)$ (Table 3).

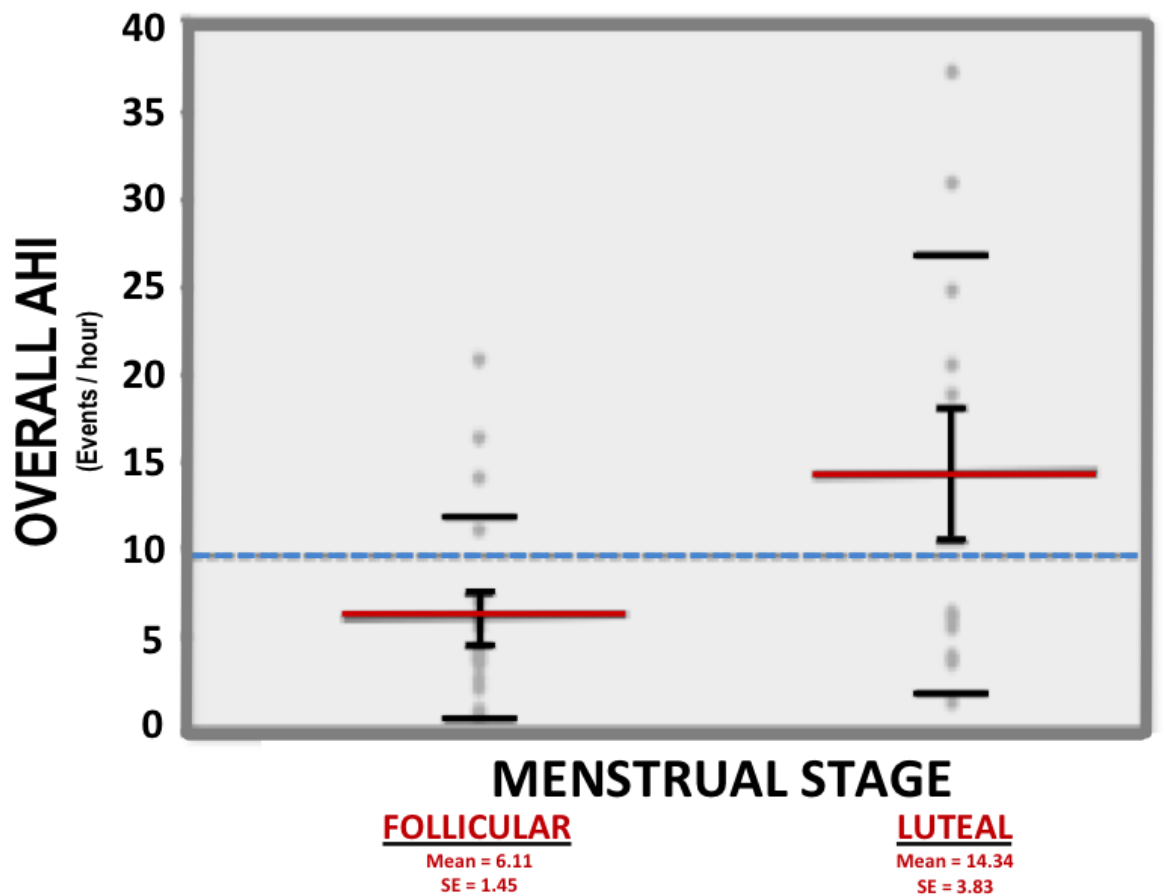

\section{FIGURE 1: Mean Overall AHI in Follicular Cohort (Left) vs. Luteal Cohort (Right).}

A one-way t-test was used to evaluate whether reduced Total AHI (apnea-hypopnea index) shares a statistically significant correlation with escalating estrogen during the follicular phase of the menstrual cycle. This one-way analysis confirms a statistically significant difference between the mean Total AHIs in the follicular versus luteal groups $(p=0.033)$. Horizontal solid bars represent the mean Total $\mathrm{AHI}$ within each group. The error bars and standard deviations are shown for each mean. The horizontal dashed line represents the mean Total AHI of all subjects.

\begin{tabular}{|c|c|c|c|c|c|c|c|}
\hline Cohort & $\mathbf{n}$ & $\mathrm{AHI}>15$ & Overall AHI & REM AHI & NREM AHI & Supine AHI & Non-Supine AHI \\
\hline Follicular & 17 & $12 \% *$ & $6.1^{*}$ & 15.1 & 3.6 & 10.2 & 3.1 \\
\hline Luteal & 11 & $46 \%$ * & $14.3^{*}$ & 30.9 & 7.8 & 20.6 & 10.0 \\
\hline
\end{tabular}

\section{TABLE 3: Summary of Polysomnography Results}

AHI: apnea-hypopnea index; NREM: non-rapid eye movement; REM: rapid eye movement 


\section{Discussion}

The epidemiology of obstructive sleep apnea (OSA) exhibits a clear gender disparity; the prevalence of OSA in men (3.9\%) is three times the prevalence in women (1.2\%) [18-20]. This male predominance of OSA disappears after the age of 50, at which time women show approximately equal prevalence to men [1]. These findings suggest that female sex hormones play a pivotal role in governing patient susceptibility to OSA, which is further supported by research showing significantly decreased levels of estrogen and progesterone in patients who have an AHI greater than 10/hour [21]. Despite this convincing evidence for a strong link between female sex hormones and obstructive sleep apnea, the influence of the menstrual cycle on PSG results has remained largely undefined.

Prior studies investigating the hormonal influence on OSA have shown conflicting results. For example, an 11-patient prospective crossover study by Driver, et al. concluded that the luteal phase of the menstrual cycle was associated with reduced upper airway resistance in premenopausal women [22]. A second 11-patient study by Stahl, et al. showed that none of the PSG sleep or breathing parameters were significantly affected by oscillating progesterone levels during the menstrual cycle [23]. Other research has found that neither the follicular nor the luteal phase altered the rate, duration, or extent of the desaturation associated with sleep disordered breathing during NREM sleep, but that the luteal phase was associated with marginal improvements in these parameters during REM sleep [24]. It is important to recognize, however, that these prior studies were conducted using normal subjects or heterogeneous sample populations incorporating both healthy and symptomatic subjects. None of the women included in the Driver, et al. study, for example, presented with symptoms concerning for OSA and only three women were ultimately found to have an AHI of greater than 10/hour [22]. We also had a larger sample size.

Our study has unique clinical relevance because it is comprised of undiagnosed, premenopausal women referred for diagnostic PSG due to high clinical concern for OSA. In this population of high-risk patients, obtaining accurate PSG results is particularly critical for optimizing the subsequent therapeutic intervention. Our results suggest that the menstrual phases have direct clinical consequences in the diagnosis of OSA; significantly higher overall AHI values were observed in women who underwent PSG during the luteal phase, and women in the luteal phase were nearly four times more likely to return a result of moderate to severe sleep apnea (Figure 1). Although NREM and REM AHI values did not reach statistical significance, this was likely due to limited sample size, and it is important to note that the statistical trends observed for all measures of AHI across the Follicular and Luteal Cohorts were consistent. These findings suggest that PSG results are partially a function of the menstrual phase.

There are several study limitations. First, our sole marker of menstrual phase was patientreported last menstrual period. Although less reliable than hormonal assays, we applied gynecologic history and patient-recalled LMP in women with menstrual regularity to predict their menstrual phase. We opted to pursue this method because it is a process that would be easy to replicate in clinical settings. Performing hormonal assays on all patients referred for diagnostic PSG, by contrast, would be impractical. Not only is patient-recalled LMP easily incorporable into the pre-PSG patient assessment, but it has also proven to be highly reliable with $81 \%$ of women correctly reporting their LMP to within two days [25]. Other study limitations include the limited number of subjects and retrospective study design.

In concordance with prior research that has shown a therapeutic benefit of short-term estrogen monotherapy, our findings suggest that the follicular phase of the menstrual cycle may induce a similarly protective effect against OSA in premenopausal women. With a nearly four-fold increase in moderate to severe OSA in the Luteal Cohort, factoring in menstrual phase could be a clinically significant improvement in obtaining a correct diagnosis and treatment plan for 
premenopausal women with symptoms of sleep apnea. Our findings could also account for why some women with symptoms of OSA have negative PSGs. Future research should explore the function of continuous positive airway pressure (CPAP) during the menstrual cycle as it is possible that different pressures are required based on these phases. An additional avenue for future research includes performing PSGs on the same women in both phases of the menstrual cycle to assess the magnitude of the AHI difference between phases.

\section{Conclusions}

The results of this study are the first to suggest that the follicular phase of the menstrual cycle has a protective effect against sleep-disordered breathing in a population of premenopausal women who were being referred for diagnostic PSG with high clinical suspicion for OSA. AHI values were significantly higher for patients who underwent PSG during the luteal phase, whereas patients undergoing PSG during the follicular phase demonstrated lower overall REM and NREM AHI values. These findings are clinically relevant because they suggest that premenopausal patients who undergo polysomnography during the first half of their menstrual cycles may present with lower AHI values on PSG, potentially leading to the inaccurate classification of OSA severity and increased morbidity. Consideration of the LMP in the scheduling and interpretation of PSG is encouraged to help minimize these risks.

\section{Additional Information}

\section{Disclosures}

Human subjects: Consent was obtained by all participants in this study. Boston University Institutional Review Board issued approval. Ethical Approval: All procedures performed in studies involving human participants were in accordance with the ethical standards of the institutional and/or national research committee and with the 1964 Helsinki declaration and its later amendments or comparable ethical standards. Informed Consent: Informed consent was obtained from all individual participants included in the study. Animal subjects: All authors have confirmed that this study did not involve animal subjects or tissue. Conflicts of interest: In compliance with the ICMJE uniform disclosure form, all authors declare the following: Payment/services info: All authors have declared that no financial support was received from any organization for the submitted work. Financial relationships: All authors have declared that they have no financial relationships at present or within the previous three years with any organizations that might have an interest in the submitted work. Other relationships: All authors have declared that there are no other relationships or activities that could appear to have influenced the submitted work.

\section{Acknowledgements}

*Dr Andrew R. Spector and Daniel B. Loriaux contributed equally to this work. Acknowledgements: Walter Lehan, RPSGT Mary-Tara Roth, RN, MSN, MPH Howard Cabral, PhD Sandra Stinnett, DrPH Justin Mhoon, MD Onyinye Iweala, MD, PhD

\section{References}

1. Bixler EO, Vgontzas AN, Lin HM, Ten Have T, Rein J, Vela-Bueno A, Kales A: Prevalence of sleep-disordered breathing in women: effects of gender. Am J Respir Crit Care Med. 2001, 163:608-13. 10.1164/ajrccm.163.3.9911064

2. Popovic RM, White DP: Upper airway muscle activity in normal women: influence of hormonal status. J Appl Physiol (1985). 1998, 84:1055-62.

3. Jia SS, Liu YH: Down-regulation of hypoxia inducible factor-1alpha: a possible explanation for the protective effects of estrogen on genioglossus fatigue resistance. Eur J Oral Sci. 2010, 118:139-44. 10.1111/j.1600-0722.2010.00712.x

4. Boukari R, Marcouiller F, Joseph V: Relative contribution of nuclear and membrane 
progesterone receptors in respiratory control. Adv Exp Med Biol. 2015, 860:261-67. 10.1007/978-3-319-18440-1 30

5. Block AJ, Wynne JW, Boysen PG: Sleep-disordered breathing and nocturnal oxygen desaturation in postmenopausal women. Am J Med. 1980, 69:75-79. 10.1016/00029343(80)90502-1

6. Manber R, Kuo TF, Cataldo N, Colrain IM: The effects of hormone replacement therapy on sleep-disordered breathing in postmenopausal women: a pilot study. Sleep. 2003, 26:163-68.

7. Rajagopal KR, Abbrecht PH, Jabbari B: Effects of medroxyprogesterone acetate in obstructive sleep apnea. Chest. 1986, 90:815-21. 10.1378/chest.90.6.815

8. Cook WR, Benich JJ, Wooten SA: Indices of severity of obstructive sleep apnea syndrome do not change during medroxyprogesterone acetate therapy. Chest. 1989, 96:262-66.

10.1378/chest.96.2.262

9. Franklin K, Lundgren R, Rabben T: Sleep apnoea syndrome treated with oestradiol and cyclic medroxyprogesterone. Lancet. 1991, 338:251-52. 10.1016/0140-6736(91)90389-7

10. Strohl KP, Hensley MJ, Saunders NA, Scharf SM, Brown R, Ingram RH Jr: Progesterone administration and progressive sleep apneas. JAMA. 1981, 245:1230-32.

10.1001/jama.1981.03310370022015

11. Keefe DL, Watson R, Naftolin F: Hormone replacement therapy may alleviate sleep apnea in menopausal women: a pilot study. Menopause. 1999, 6:196-200.

12. Block AJ, Wynne JW, Boysen PG, Lindsey S, Martin C, Cantor B: Menopause, medroxyprogesterone and breathing during sleep. Am J Med. 1981, 70:506-10. 10.1016/00029343(81)90572-6

13. Pickett CK, Regensteiner JG, Woodard WD, Hagerman DD, Weil JV, Moore LG: Progestin and estrogen reduce sleep-disordered breathing in postmenopausal women. J Appl Physiol (1985). 1989, 66:1656-61.

14. Cistulli PA, Barnes DJ, Grunstein RR, Sullivan CE: Effect of short-term hormone replacement in the treatment of obstructive sleep apnoea in postmenopausal women. Thorax. 1994, 49:699-702. 10.1136/thx.49.7.699

15. Polo-Kantola P, Rauhala E, Helenius H, Erkkola R, Irjala K, Polo O: Breathing during sleep in menopause: a randomized, controlled, crossover trial with estrogen therapy. Obstet Gynecol. 2003, 102:68-75. 10.1016/S0029-7844(03)00374-0

16. Wesström J, Ulfberg J, Nilsson S: Sleep apnea and hormone replacement therapy: a pilot study and a literature review. Acta Obstet Gynecol Scand. 2005, 84:54-57. 10.1111/j.00016349.2005.00575.X

17. Shahar E, Redline S, Young T, Boland LL, Baldwin CM, Nieto FJ, O'Connor GT, Rapoport DM, Robbins JA: Hormone replacement therapy and sleep-disordered breathing. Am J Respir Crit Care Med. 2003, 167:1186-92. 10.1164/rccm.200210-12380C

18. Mohsenin V: Effects of gender on upper airway collapsibility and severity of obstructive sleep apnea. Sleep Med. 2003, 4:523-29. 10.1016/S1389-9457(03)00168-0

19. Dursunoğlu N: Effects of menopause on obstructive sleep apnea. Tuberk Toraks. 2009, 57:10914.

20. Redline S, Kump K, Tishler PV, Browner I, Ferrette V: Gender differences in sleep disordered breathing in a community-based sample. Am J Respir Crit Care Med. 1994, 149:722-26. 10.1164/ajrccm.149.3.8118642

21. Netzer NC, Eliasson AH, Strohl KP: Women with sleep apnea have lower levels of sex hormones. Sleep Breath. 2003, 7:25-29. 10.1007/s11325-003-0025-8

22. Driver HS, McLean H, Kumar DV, Farr N, Day AG, Fitzpatrick MF: The influence of the menstrual cycle on upper airway resistance and breathing during sleep. Sleep. 2005, 28:44956.

23. Stahl ML, Orr WC, Males JL: Progesterone levels and sleep-related breathing during menstrual cycles of normal women. Sleep. 1985, 8:227-30.

24. Edwards N, Wilcox I, Sullivan CE: Sleep apnoea in women. Thorax. 1998, 53:S12-S15. 10.1136/thx.53.2008.S12

25. Wegienka G, Baird DD: A comparison of recalled date of last menstrual period with prospectively recorded dates. J Womens Health (Larchmt). 2005, 14:248-52.

10.1089/jwh.2005.14.248 